\section{Characterisation of a new protocol for mortar dating: ${ }^{14} \mathrm{C}$ evidences}

\author{
Fabio Marzaioli,, ${ }^{1,2}$ Carmine Lubritto, ${ }^{3}$ \\ Sara Nonni, ${ }^{4}$ Isabella Passariello, ${ }^{2}$ \\ Manuela Capano, ${ }^{3}$ Luca Ottaviano, ${ }^{5}$ \\ Filippo Terrasi ${ }^{1,2}$ \\ 'Dipartimento di Matematica e Fisica, \\ Seconda Università degli Studi di Napoli, \\ Caserta; 'INNOVA Centre for Isotopic \\ Research on Cultural and Environmental \\ heritage - CIRCE, Seconda Università \\ degli Studi di Napoli, Caserta; \\ ${ }^{3}$ Dipartimento di Scienze e Tecnologie \\ Ambientali Biologiche e Farmaceutiche, \\ Seconda Università degli Studi di Napoli, \\ Caserta; ${ }^{4}$ Dipartimento di Scienze della \\ Terra, Università La Sapienza, Roma; \\ ${ }^{5}$ Dipartimento di Scienze Fisiche e \\ Chimiche, Università degli Studi \\ dell'Aquila, L'Aquila, Italy
}

\section{Abstract}

Mortars represent a class of material basically constituted by a mixture of different phases (i.e. binder, aggregates, water) and widespread used for constructive uses and artworks. Current scientific literature regarding the possibility of mortar radiocarbon dating reports different and still contradictory results. Most of the observed inaccuracy of the dating method often derives from the presence of carbonaceous residuals of limestone origins drastically increasing the mortar age estimation contributing with significant aliquots of dead carbon. Most of the existing methodologies aim to isolate binder from other materials, preserving a trace of the ${ }^{14} \mathrm{C}$ signature of the atmosphere absorbed during mortar setting. In this work a series of measurements (i.e. $\% \mathrm{C}$ and ${ }^{14} \mathrm{C}$ ) of different matrices involved in the mortar production process simulated in a simplified version in the laboratory environment will be shown. More in detail the isotopic signature of the $\mathrm{CO}_{2}$ present in the laboratory air during mortar setting is compared with the signal extracted from the synthesised mortar by means of a separation protocol of the binder. Our analyses are performed with the aim to evaluate this procedure of dead $\mathrm{C}$ suppression efficiency for accurate mortar radiocarbon dating.

\section{Introduction}

Lime mortars preserve the potential to define the absolute chronology of a study site by means of radiocarbon $\left({ }^{14} \mathrm{C}\right)$ because only during their hardening, happening on timescales negligible with respect to ${ }^{14} \mathrm{C}$ half life, they absorb big aliquots of atmospheric $\mathrm{CO}_{2}$ recording the time of development of a given artifact (Van Strydonck et al., 1986) in an anthropogenic (secondary) carbonate buffer. The opportunity to apply the ${ }^{14} \mathrm{C}$ dating tool to mortars constitutes a possible breakthrough point in the actual knowledge because mortar represents a class of materials widespread over the archaeological sites. Archaeologists dated the earliest usage of mortars to Egyptians (4000 B.C.) (Boynton, 1980) and it is well documented how the Roman empire did a massive usage of them well characterising the protocols for their preparation and usage (Vitruvius, 1931).

Moreover, dating of mortars, in principle, represents an unbiased chronological anchor for the study of buildings and other structures previously estimated (not directly) by dating organic materials, when found, in the context of the study site. It is well documented, for example, how in some cases timbers are made from materials aged and/or recycled before their usage leading to some systematic error in their timescale estimation (Ringbom et al., 2003 ). Since the 1960 s radiocarbon community began investigating the potential of mortars to serve as a chronometer for the determination of the ages of structures (Delibrias and Labeyrie, 1964; Folk and Valastro, 1976; Van Strydonck et al., 1986; Heineimer et al., 1997; Sonninen and Junger, 2001). To date observed variability of the radiocarbon results lead to a still unclear methodology to prosecute with the aim of repeatable accurate dating. Scientific evidences indicate how most of these uncertainties are attributable to the lime mortar production and environmental exposure processes: i) limestone carbonate residues, which may take origin from the incomplete cooking of the limestone (primary carbonate) during the quicklime $(\mathrm{CaO})$ production, add a dead $\mathrm{C}$ $\left({ }^{14} \mathrm{C}\right.$ free) carbonate fraction leading to age overestimations; ii) calcareous sand which adds an ageing effect similar to the dead $\mathrm{C}$ residue of the primary carbonate being formed from materials virtually free of ${ }^{14} \mathrm{C}$; iii) aggregates, any type of material, from reworked bricks and marble to stone waste bringing different aliquots of ${ }^{14} \mathrm{C}$ hence altering the fingerprint (in the case of carbonatic elements) and/or drastically altering the mechanism of hardening of the mortar; iv) running water containing dissolved $\mathrm{CO}_{2}$ can cause a supplementary deposit (ternary carbonates) on the mortar or an exchange in carbonate ions.

While contaminant sources described in points 2 to 4 can be suppressed by means of different kind of procedures regarding the choice of the most appropriate sample (i.e. not
Correspondence: Fabio Marzaioli, Dipartimento di Matematica e Fisica, Seconda Università degli Studi di Napoli, viale Lincoln 5, 8100 Caserta, Italy. Tel/Fax: +39.082.3274814

E-mail: fabio.marzaioli@unina2.it

Key words: isotope methodologies, radiocarbon dating, laboratory accuracy evaluation, cultural heritage absolute chronology.

Citation: Marzaioli F, Lubritto C, Nonni S, Passariello I, Capano M, Ottaviano L, Terrasi F 2014. Characterisation of a new protocol for mortar dating: 14C evidences. In: RH Tykot (ed.), Proceedings of the $38^{\text {th }}$ International Symposium on Archaeometry - May $10^{\text {th }}-14^{\text {th }} 2010$, Tampa Florida. Open Journal of Archaeometry 2:5264.

Presented at the $38^{\text {th }}$ International Symposium on Archaeometry - May $10^{\text {th }}-14^{\text {th }} 2010$, Tampa, Florida.

This work is licensed under a Creative Commons Attribution 3.0 License (by-nc 3.0).

(C) Copyright F. Marzaioli et al., 2014

Licensee PAGEPress, Italy

Open Journal of Archaeometry 2014; 2:5264

directly exposed to the environment but not completely screened by the $\mathrm{CO}_{2}$ interaction) and the exclusion of aggregates as efficient as possible, primary carbonate dead $\mathrm{C}$ contamination (point 1) is the most relevant source of bias of aerial mortars (Van Strydonck et al. 1986).

Very often the definition of success for these protocols is based on the comparison between radiocarbon data and the expected artifact age. It is our opinion that the definition of the feasibility of a protocol should follow a pathway of increasing complexity allowing the isolation of factors co-contributing to the total uncertainty observed in literature (i.e. from point 1 to point 4 in our case). This kind of procedure testing is useful to define eventual adjustments of the initial methodology in response to the pitfalls observed along the experimental pathway from the simplified to the field mortars definitively validating the protocol.

This paper describes the laboratory testing of dating accuracy for an innovative procedure aiming to isolate the binder signal from a series of simplified mortars produced in the laboratory environment. In order to assess only the efficiency in primary carbonate dead C suppression of the proposed methodology, our mortar production procedure (Figure 1) simulates mortar production process with the exception of inert adding (points 2 and 3 ) and ageing due to their environment exposure (point 4). An efficient protocol for the age measurement of these materials must isolate, from other $\mathrm{C}$ sources, only the signal of the 
$\mathrm{CO}_{2}$ absorbed during the hardening of mortars. Lab produced mortars allows the evaluation of procedure dead $\mathrm{C}$ suppression efficiency by means of the comparison between the procedure extracted binder phases and the laboratory air $\mathrm{CO}_{2}$ signal sampled during the hardening of the mortars.

\section{Materials and Methods}

\section{Laboratory mortar synthesis and characterisation}

Mortar production process applied for this study simulates the common production phases of mortar materials. For our purposes (see the introduction for details) no inert (carbonaceous or not) aggregates were added. Those materials are used in real mortars, with a typical 1:3 to 1:4 binder/aggregate ratio, aiming to increase mortar workability, avoid cracks formation during mortar hardening (Cazalla et $a l ., 2000$ ) and enhance hydration (Lawrence $e t$ al., 2003). Details are provided in Figure 1.

\section{Primary carbonate characterisation and sampling}

A carbonatic rock of about $30 \mathrm{~kg}$ was randomly sampled by hammering and 3 produced scraps of about 2 grams were powdered to characterise the initial limestone carbonate $\left(\mathrm{CaCO}_{3}\right.$ i.e. $\% \mathrm{C}$, XRD and $\left.{ }^{14} \mathrm{C} / 2 \mathrm{C}\right)$.

\section{Quicklime production and characterisation}

Calcium oxide $(\mathrm{CaO})$ is historically produced by means of thermal dissolution (calcination) of the primary carbonate releasing gaseous $\mathrm{CO}_{2}$ (Felder-Casagrande et al., 1997). For our experiment, 6 pieces (10-15 $\mathrm{g}$ of material) of primary carbonate underwent to calcination in a muffle oven, capable to reach up to $1100^{\circ} \mathrm{C}$, at different temperatures (i.e. 700, 800, 900, 1000, $1100^{\circ} \mathrm{C}$ ) for 1 hour and 1.5 hours (i.e 700_1.5), with the aim to asses the eventual effects of temperature and time on the quality of the produced quicklimes (QL700, QL700_1.5, QL800, QL900, QL11000 and QL1100). A muffle oven was run automatically with a cycle reaching the set temperature in about 1 hour, maintained for the specified time, and let decrease to ambient temperature (some hours) before sample removal. Chosen temperature interval was centered in the literature observed optimum for limestone calcination (i.e. $900^{\circ} \mathrm{C}$ ) also used for the historic limekiln production (Mouropoulou et al., 2001). A fraction (500 mg) of the produced quicklimes was sampled for $\% \mathrm{C}$ and ${ }^{14} \mathrm{C}$ analysis.

Slaked lime production/carbonatation and mortar characterisation

Slaked lime $\left[\mathrm{Ca}(\mathrm{OH})_{2}\right]$ is produced by sub- merging quick limes in an excess of water and preserved in this form (i.e. lime putty) for long periods [some years (Cazalla et al., 2000)]. Lime putty mixed with inert materials is used as a binder for different uses, hardening because of atmospheric $\mathrm{CO}_{2}$ absorption (carbonatation) and water loss, hence becoming (secondary) carbonate. Carbonatation of slaked lime is controlled by two main reaction limiting the kinetic of the reaction: i) the dissolution of $\mathrm{CO}_{2}$ in the water phase; ii) the consumption of $\mathrm{CO}_{2}$ during the reaction with $\mathrm{Ca}(\mathrm{OH})_{2}$. The solubility of carbon dioxide and slaked lime decreases with increasing temperature, whereas chemical reactions in general are faster with increasing temperature.

So we decided to realise a triple step hydration/carbonation process exposing slaked lime to our natural laboratory air. During the first hour watered materials were put in an ultrasonic bath to increase the hydration efficiency producing a lime putty. During the second phase, lasted three weeks, samples were kept in a temperature controlled environment at $4^{\circ} \mathrm{C}$ with the aim to speeding up the $\mathrm{CO}_{2}$ dissolution in the ultra-basic water phase. The third phase, lasted two weeks, was performed at laboratory temperature $\left(25^{\circ} \mathrm{C}\right.$ controlled) to facilitate the real lime carbonatation process. Produced mortars (M700, M700_1.5, M800, M900, M1000 and M1100) were sampled with the aim to evaluate $\mathrm{C}$ abundances and M700 and M900 underwent to scanning electron microscopy (SEM) methodology. Laboratory air $\mathrm{CO}_{2}$ purification and characterisation

Over the carbonatation period, laboratory natural air was processed with the aim of $\mathrm{CO}_{2}$ extraction. About $3 \mathrm{~L}$ of air necessary to isolate $2 \mathrm{mg}$ of $\mathrm{CO}_{2}$ were forced to pass through a cryogenic purification line (Bertolini et al., 2005) by means of a rough pumping system. This line, avoiding process induced isotope discriminations by means of temperature controlled spiral traps, allows the isolation of atmospheric $\mathrm{CO}_{2}$ and its successive ${ }^{14} \mathrm{C}$ characterisation.

\section{Protocol for the isolation of the binder phase from the laboratory mortars}

Our procedure scheme is based on the finding of an evident difference in the aggregation habit of the secondary versus primary carbonate. Moorehead (1986) found how most of the calcium carbonates constituting ancient mortars are amorphous or very poor crystalline forms of calcite and several authors attribute to the secondary carbonate a powdery, porous, acid fast reacting and fine grained structure (Delibrias and Labeyrie 1964; Folk and Vallastro, 1976). These differences can be used to discriminate between the origins (anthropogenical versus geological) of the examined carbonates. Our experimentation is funded on the assumption of a finer and more fragile

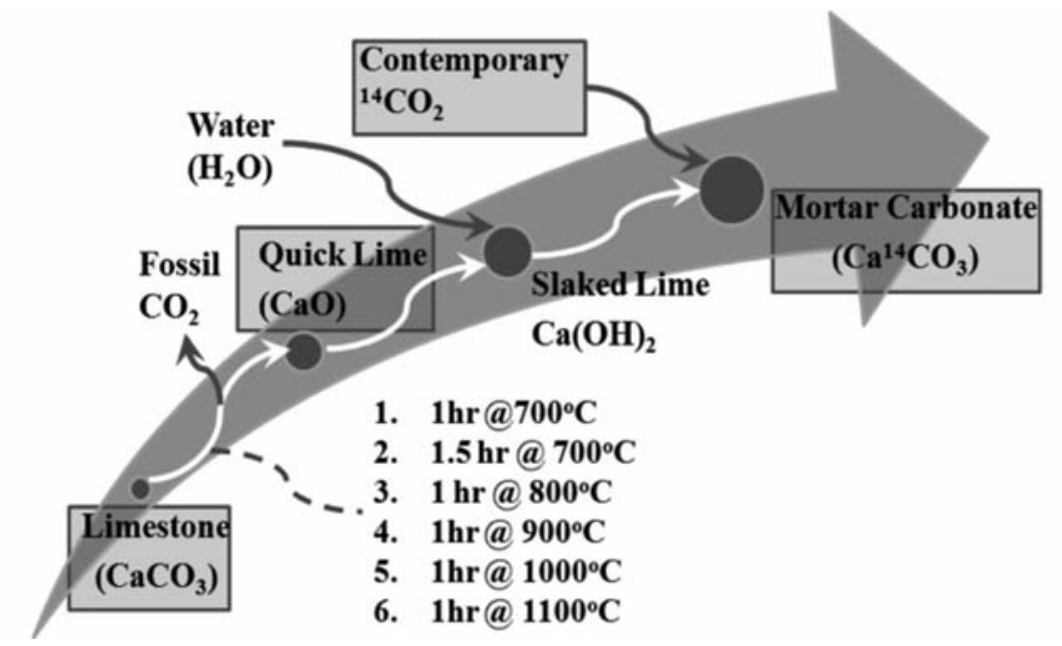

Figure 1. Scheme of the laboratory procedure applied for the production of synthetic mortar. Calcination was applied by means of a combination of different reaction times and temperatures. Shaded box matrices underwent ${ }^{14} \mathrm{C}$ and, with the exception of contemporary ${ }^{14} \mathrm{CO}_{2}, \% \mathrm{C}$ characterisation. 
aggregation structure of the secondary carbonate and tends to its isolation by means of a laboratory defined procedure. The core of the procedure is the ultrasonication of mortars which, after powdering, gross selection and watering with decarbonicated/deionised water, is supposed develop the selective suspension of secondary carbonates allowing their isolation and characterisation. In details, produced mortars were broken by means of hammering and submerged in about $50 \mathrm{~mL}$ of water in beakers. Beakers with mortars were ultrasonicated for 1 hour leaving the finer particles, characterised by a slower sedimentation velocity in suspension. Suspensions were gently siphoned in polypropylene centrifuge tubes, avoiding lower phase re-suspension, and solid particles isolated by means of $6000 \mathrm{rpm}$ centrifuging for 10 minutes. Overnight dried suspension (i.e. S700, S700_1.5, S800, S900, S1000 and S1100) were analysed for the measurement of their ${ }^{14} \mathrm{C}$ content. S700 and S900 were characterised also with SEM methodology.

\section{\%C analyses}

Three samples of the initial limestone $\left(\mathrm{CaCO}_{3}\right)$, together with produced quicklimes (QL) and mortars (M) in three replicas underwent to elemental $\mathrm{C}$ analyses. Briefly, samples were weighted in variable amounts in tin cups, ensuring a detectable peak signal. A Flash EA 1112 (Thermo Fisher Scientific Inc., Waltham, MA, USA) was run in automated mode and calibration plus check (a standard run as an unknown) marble standard were used to calibrate acquired signals and evaluate procedure accuracy/precision.

\section{Scanning electron microscopy/ \\ $\mathrm{X}$-ray diffraction analyses}

The powder was loaded in the tray of Phillips PW 1800 XRD (Phillips, Amsterdam, The Netherlands) machine and spectra acquired by using a Co K-alpha radiation.

SEM images were taken with a LEO 1503 apparatus equipped with a field effect gun. The beam was typically operated at $1 \mathrm{kV}$.

\section{${ }^{14} \mathrm{C}$ analyses}

Radiocarbon determinations of carbonaceous materials $\left(\mathrm{CaCO}_{3}, \mathrm{QL}, \mathrm{M}\right.$ and $\left.\mathrm{S}\right)$ were performed on the $\mathrm{CO}_{2}$ evolved by means of a complete $\mathrm{H}_{3} \mathrm{PO}_{4}$ vacuum digestion (McCrea, 1950). A variable amount (30 to $200 \mathrm{mg}$ ) of materials, depending on their $\% \mathrm{C}$, capable to ensure about $2 \mathrm{mg}$ of $\mathrm{C}$ was weighted. Acid digestion produced $\mathrm{CO}_{2}$ was cryogenically purified and, together with the previously purified laboratory air $\mathrm{CO}_{2}$, graphitised according to zinc process (Marzaioli et al., 2008). Graphite was measured by means of the CIRCE AMS system for the determination of radiocarbon isotopic ratios (Terrasi et al., 2008).
For the purposes of this study radiocarbon abundances are expressed according to the radiocarbon age (R.C. age) and percent of modern carbon (pMC) notation (Stuiver and Pollach, 1977):

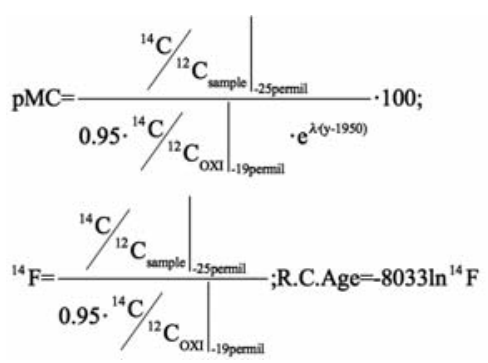

with the radiocarbon isotopic ratios of the sample and the oxalic acid I (OXI) primary radiocarbon standard corrected for mass dependent isotopic fractionation and the OXI corrected for radioactive decay to 1950 in the pMC notation. R.C. ages were calibrated by means of the $0 x \mathrm{xCal} 4.1$ calibration program (Ramsey, 2009) using INTCAL 09 (Reimer et al., 2009) calibration dataset.

\section{Data analysis}

Where not explicity stated, multiple measurements are expressed as individual error weighted averages. Dispersion of the data is expressed by the standard error (external error) or the weighted average error (internal error) depending on the result of a $\chi^{2}$ test performed to check whether or not the latter value well express measurement variability.
Comparison of values is performed by means of a t test for the means expressing the level of agreement at $5 \%$.

\section{Results and Discussion}

\section{Primary Carbonate}

The primary carbonate was characterised by means of X Ray Diffractometry (XRD) in order to better constraint its mineralogy. XRD analysis confirms the low magnesium tenor of the calcite crystals analysed. Carbon \% of the initial carbonate is $10.2 \pm 0.2$ (average \pm standard error). Averaged pMC on three samples of the primary carbonate was $0.12 \pm 0.05 \%$ leading to an equivalent R.C. age of $54025 \pm 3347$ a. Presented results, being in general agreement with the expected values (i.e. \%C around $12 \%$ and low radiocarbon contents), confirm the feasibility of the sampled rock for the production of lime mortars.

\section{Quicklimes}

The QL 700, QL 700_1.5, QL 800, QL 900, QL 1000 and QL1100 \%C evidence a different response of the primary carbonate to calcination reaction with respect to treatment temperature (Figure 2). It is evident how roughly two subgroups of quicklimes can be identified: i) QL 700 and QL 700_1.5 \%C depleted (about $20 \%$ of $\mathrm{C}$ less) with respect to the primary carbonate but with still sensitive amounts of residual primary $\mathrm{C}$ : ii) other QL samples char-

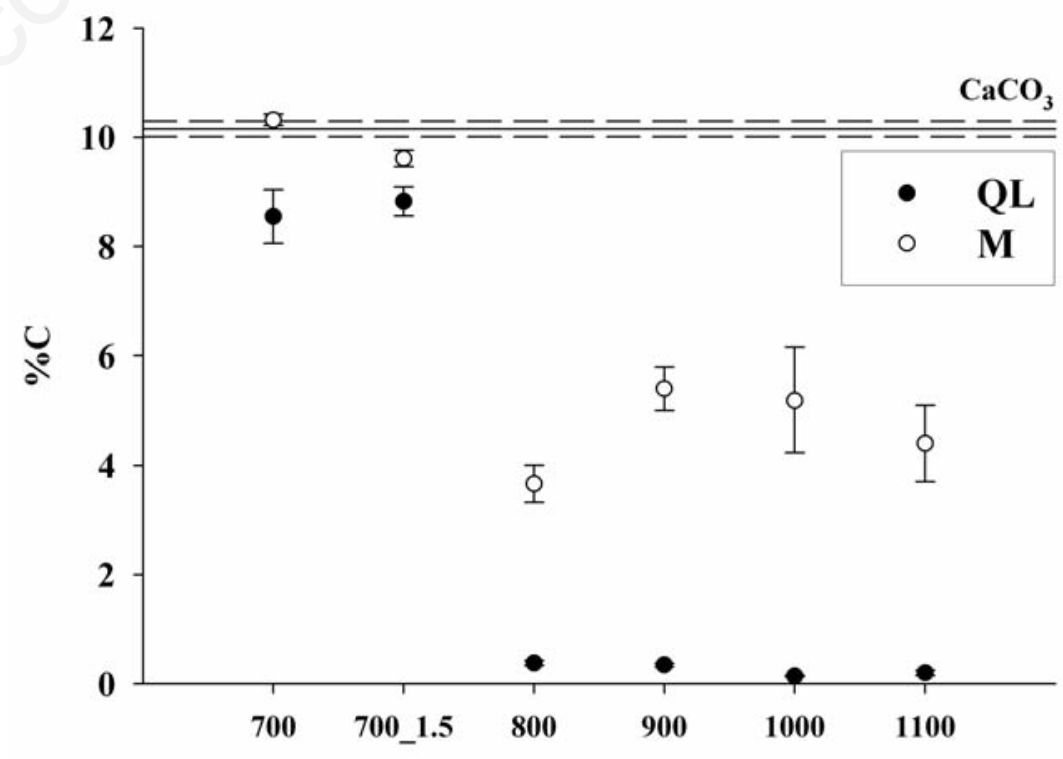

Figure 2. Measured (mean \pm standard error) $\mathrm{C}$ contents $(\% \mathrm{C})$ of the limestone $\left(\mathrm{CaCO}_{3}\right.$ continuous line), quicklimes ( $Q \mathrm{~L}$ full circles) and mortars ( $\mathrm{M}$ empty circles). The horizontal axis is referred to the temperature of production of the quicklime (see text for details). 
acterised by less than $1 \%$ of calcination residual $\mathrm{C}$ with its \% decreasing with increasing temperature. Our data are fully in agreement with the current knowledge about the lime kiln (Moropolou et al., 2001) reaching a calcination optimum for temperatures around $900^{\circ} \mathrm{C}$. It must be stressed here that, because of the first subgroup of QLs is produced at about $200^{\circ} \mathrm{C}$ less than the thermal decomposition window for the calcite minerals [i.e. Boynton (1980) found thermal dissolution of calcite happens at $898^{\circ} \mathrm{C}$ at 1 bar of pure $\mathrm{CO}_{2}$ pressure], they do represent, because of a low degree of hardening, a kind of materials scarcely applicable for constructive purposes.

Weighted average on QL 700 and QL 700_1.5 radiocarbon content was $1.1 \pm 0.8 \mathrm{pMC}$ confirming that calcination does not alter radiocarbon signature of residual $\mathrm{C}$.

\section{Mortars}

$\% \mathrm{C}$ of mortars confirms the overall success

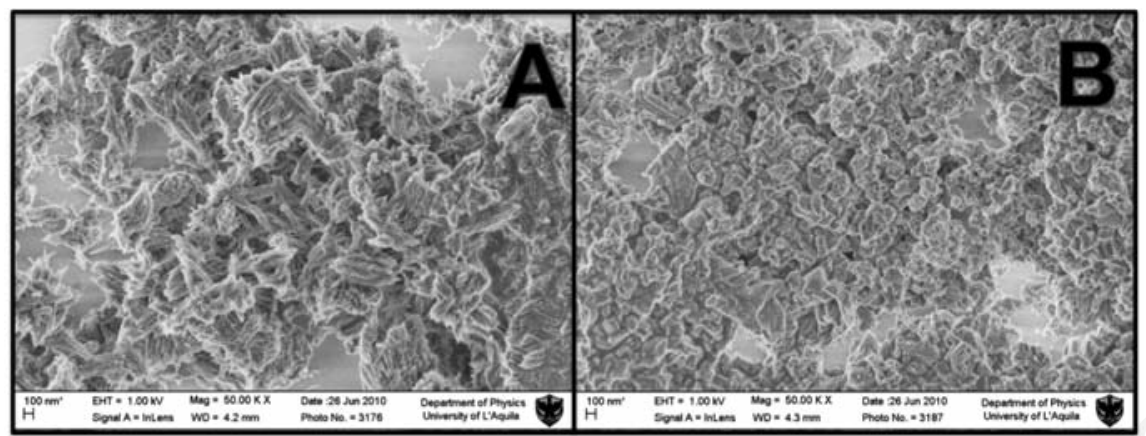

Figure 3. Scanning electron microscope images of the 700 (A) and 900 (B) laboratory produced mortars (M).

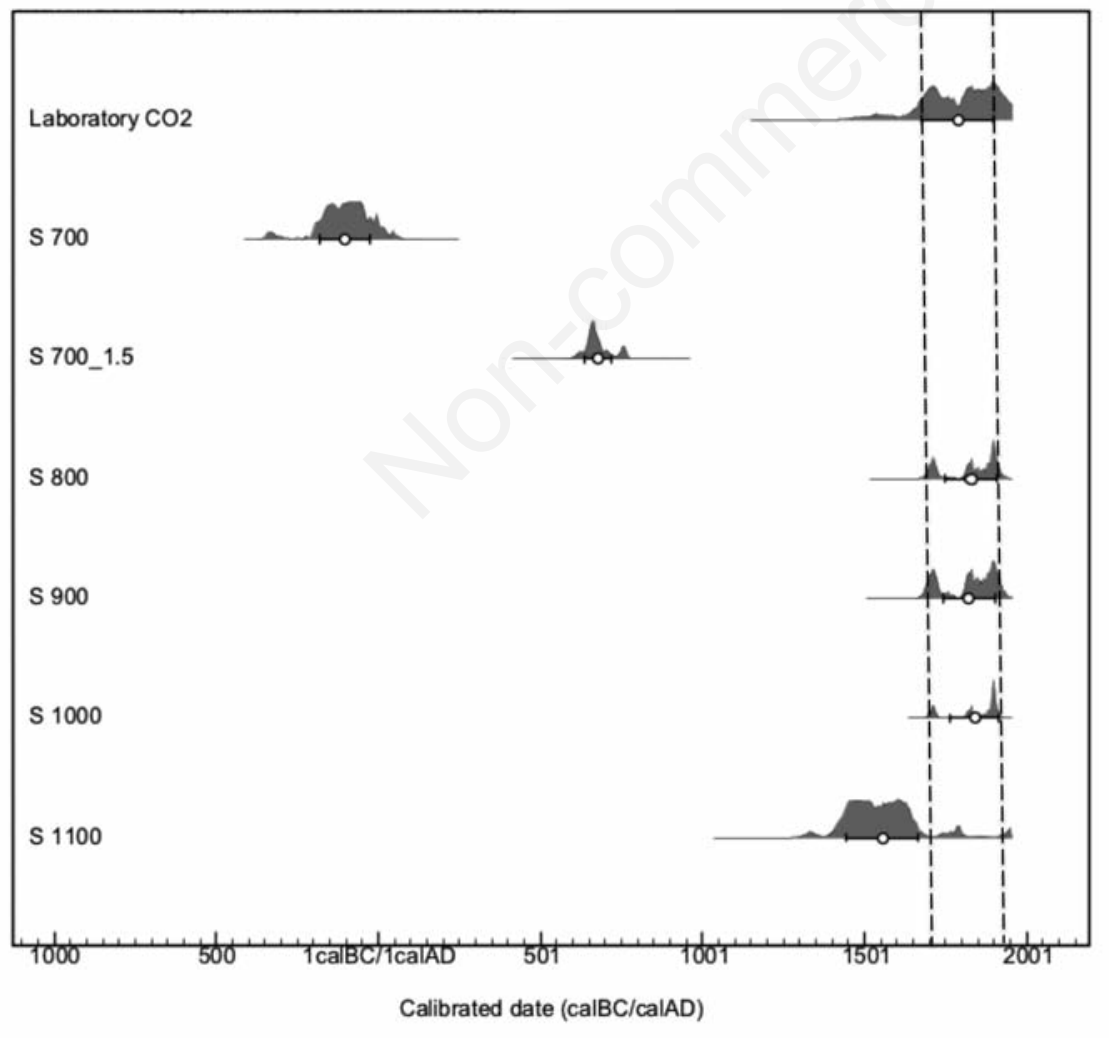

Figure 4. Calibrated dates (Ramsey, 2009) of the ${ }^{14} \mathrm{C}$ measurements of suspensions isolated by the laboratory produced mortars compared with the apparent age of the Laboratory $\mathrm{CO}_{2}$ (evidenced by the dashed line) sampled over the carbonatation period. For each measurement mean $(\mathrm{m})$ and 1 standard deviation $(\mathrm{s})$ interval is represented. of the laboratory carbonatation procedure (Figure 2). Looking at the data it is possible to define two subgroups of produced mortars: i) the M700 and M700_1.5 characterised by C contents not statistically different by the limestone carbonate: ii) the other carbonates characterised by $\% \mathrm{C}$ around $5 \%$ independently by their production history. Morphological differences between the groups are either strongly evidenced by SEM images (Figure 3).

\section{Suspensions}

A general ${ }^{14} \mathrm{C}$ enrichment of the suspensions, varying from 200 to $5 \%$, with respect to the mortars is evident for all the measured samples implying the overall validity of the applied selection criteria. With the exception of S700 and S700_1.5, measured radiocarbon values showed a high reproducibility (i.e. pMC $98 \pm 1 \%$ ) comparable to the measured atmosphere variability (See the paragraph below) over the carbonatation period (Figure 4).

\section{Atmosphere}

Measured ${ }^{14} \mathrm{C}$ values on the two spot samples of cryogenically purified $\mathrm{CO}_{2}$ lead to a pMC of $100 \pm 2 \%$ with a calibrated age of $1788 \pm 110$ $(\mathrm{m} \pm \mathrm{s}) \mathrm{AD}$ (Figure 4).

\section{Evaluation of the effectiveness of the protocol}

The protocol effectiveness in the primary carbonate contamination suppression from the mortars is verifiable by the comparison between the radiocarbon signatures of suspensions, according to our hypothesis isolating the carbonates of atmospheric origins composing the mortar, and the atmosphere. Radiocarbon measurements of protocol isolated suspensions highlight the successful character of the proposed protocol for the isolation of the secondary carbonates allowing the accurate dating of mortars. All the $\mathrm{RC}$ ages of the protocol isolated suspensions, with the exception of S700 and S700_1.5 achieved by strongly contaminated and scarcely usable mortars, were in agreement with the equivalent $\mathrm{RC}$ age of the laboratory atmospheric $\mathrm{CO}_{2}$ (Figure 4). This result clues the good effectiveness in the isolation of the binder signal for the proposed protocol suggesting its applicability to real mortars.

\section{Conclusions}

The opportunity offered by the carbonatation process (atmospheric $\mathrm{CO}_{2}$ adsorption), leading to the hardening of the mortars during their usage for constructive or artistic usages have been widely tested by the radiocarbon community aiming to evaluate absolute 
chronology of artifacts. The presence of unburned primary limestone, survived to the mortar production technology, was found to be one of the main responsible to drastically alter the radiocarbon age of mortars by introducing big aliquots of dead $\mathrm{C}$. This study by simulating a simplified mortar production process evaluates the capability a newly formulated protocol for mortar radiocarbon dating. The protocol, based on the isolation of a suspension of carbonaceous materials by means of strong ultrasonic attacks, was able to ensure an efficient suppression of dead C contamination for simplified mortars produced according to conventionally utilised temperatures $\left(800-1100^{\circ} \mathrm{C}\right)$.

\section{References}

Bertolini T, Rubino M, Lubritto C, D’Onofrio A, Marzaioli F, Passariello I, Terrasi F, 2005. Optimized sample preparation for isotopic analyses of $\mathrm{CO}_{2}$ in air: systematic study of precision and accuracy dependence on driving variables during $\mathrm{CO}_{2}$ purification process. J Mass Spectrom 40:1104-8.

Boynton RS, 1980. Chemistry and technology of lime and limestone. John Wiley and Sons, New York.

Cazalla 0, Rodriguez-Navarro C, Sebastian E, Cultrone G, De la Torrre MJ, 2000. Aging of lime putty: effects on traditional lime mortars carbonation. J Am Ceram Soc 83:1070.

Delibrias G, Labeyrie J, 1964. Dating of old mortars by the carbon-14 method. Nature
201:742.

Felder-Casagrande S, Wiedemann HG, Rellers E, 1997. The calcination of limestone: Studies on the past, the presence and the future of a crucial industrial process. $\mathrm{J}$ Therm Anal 49:971-8.

Folk RL, Valastro S Jr., 1976. Successful technique for dating of lime mortar by carbon14. J Field Archaeol 3:203-8.

Heinemeier J, Jungner $\mathrm{H}$, Lindroos $\mathrm{A}$, Ringbom A, von Konow T, Rud N, 1997. AMS $14 \mathrm{C}$ dating of lime mortar. Nucl Instrum Methods Phys Res B 123:487-95.

Lawrence P, Cyr M, Ringot E, 2003. Mineral admixtures in mortars effect of inert materials on short-term hydration. Cement Concrete Res 33:1939-47.

Marzaioli F, Borriello G, Passariello I, Lubritto C, De Cesare N, D'Onofrio A, Terrasi F, 2008. Zinc reduction as an alternative method for Accelerator Mass Spectrometry (AMS) radiocarbon dating: process optimization at CIRCE. Radiocarbon 50:13949.

McCrea M, 1950. On the isotopic chemistry of carbonates and a paleotemperature scale. J Chem Phys 18:849-57.

Moorehead DR, 1986. Cementation by the carbonation of hydrated lime. Cement Concrete Res 16:700-8.

Moropoulou A, Bakolas A, Aggelakopoulou E, 2001. The effects of limestone characteristics and calcination temperature to the reactivity of the quicklime. Cement Concrete Res 31:633-9.

Ramsey BC, 2009. Bayesian analysis of radiocarbon dates. Radiocarbon 51:337-60.
Reimer PJ, Baillie MGL, Bard E, Bayliss A, Beck JW, Blackwell PG, Bronk Ramsey C, Buck CE, Burr GS, Edwards RL, Friedrich M, Grootes PM, Guilderson TP, Hajdas I, Heaton TJ, Hogg AG, Hughen KA, Kaiser KF, Kromer B, McCormac FG, Manning SW, Reimer RW, Richards DA, Southon JR, Talamo S, Turney CSM, van der Plicht J, Weyhenmeyer CE, 2009. INTCAL 09 and MARINE 09 radiocarbon age calibration curves, 0-50,000 years Cal BP. Radiocarbon 51:1111-50.

Ringbom A, Hale J, Heinemeier J, Lancaster L, Lindroos A, 2003. Dating ancient mortar. Am Sci 91:130-7.

Sonninen E, Jungner H, 2001. An improvement in preparation of mortar for radiocarbon dating. Radiocarbon 43:271-3.

Stuiver M, Polach HA, 1977. Discussion: reporting of 14C Data. Radiocarbon 19:355-63.

Terrasi F, De Cesare N, D’Onofrio A, Lubritto C, Marzaioli F, Passariello I, Rogalla D, Sabbarese C, Borriello G, Casa G, Palmieri A, 2008. High precision ${ }^{14} \mathrm{C}$ AMS at CIRCE. Nucl Instrum Methods Phys Res B 266: 2221-2.

Van Strydonck M, Dupas M, Dauchot-Dehon M, Pachiaudi Ch., Marechal J, 1986. The influence of contaminating carbonate and the variations of ${ }^{13} \mathrm{C}$ in mortar dating. Radiocarbon 28:702-10.

Vitruvius, 1931 (Translation). De Architectura. Book II, V. Frank Granger's translation. Heinemann, Portsmouth, NH, USA. 